\title{
Yerli ve Yabancı Yatırımcılara Ait Risk İştahlarının İncelenmesi: Türkiye Örneği
}

Taha Bahadir SARAÇ, Department of Economics, Faculty of Economics and Administrative Sciences, Nigde University, Turkey; e-mail: tbsarac@nigde.edu.tr

Ömer ISKENDEROĞLU, Department of Business Administration, Faculty of Economics and Administrative Sciences, Nigde University, Turkey; e-mail: oiskenderoglu@nigde.edu.tr

Saffet AKDA $\breve{G}$, Department of Accounting and Tax Applications, Akdagmadeni Vocational School, Bozok University, Turkey; e-mail: saffet.akdag@bozok.edu.tr

\section{Investigation of Domestic and Foreign Investors' Risk Appetite: The Case of Turkey}

\begin{abstract}
In this study, the predictability of the risk appetite data published by the Central Registry Agency of Turkey (CRA) on a weekly basis for domestic and foreign investors which are considered as a measure of financial stability is examined. By examining the data of the period between the years 2008 - 2013, Lee and Strazicich (2003) test which takes structural breaks into account and Caner and Hansen (2001) threshold unit root test besides the first-generation unit root tests such as ADF and KPSS are performed in the study. The results obtained from the study reveal that the risk appetite data for domestic investors are linear and that there is no threshold effect. The data series of risk appetite for foreign investors, on the other hand, has been detected to be non-linear along with the existence of threshold effect. Furthermore, foreign investors' risk appetite can be predicted during the periods of a downward trend, while it cannot be predicted during the periods of an upward trend.
\end{abstract}

Keywords $\quad$ : Risk, Risk Appetite, Non-Linear Unit Root Test.

JEL Classification Codes : G12, G17, C22.

\section{Öz}

$\mathrm{Bu}$ çalışmada Türkiye'de Merkezi Kayıt Kuruluşu (MKK) tarafindan haftalık bazda yayınlanan ve finansal istikrar ölçüsü olarak kabul edilen, yerli ve yabancı yatırımcılara ait risk iştahı verilerinin tahmin edilebilirliği incelenmiştir. 2008 - 2013 dönemlerindeki verilerin incelendiği çalışmada ADF, KPSS gibi birinci nesil birim kök testlerinin yanında yapısal kırılmayı dikkate alan Lee ve Strazicich (2003) testi ile Caner ve Hansen (2001) eşikli birim kök testi gerçekleştirilmiştir. Çalışmadan elde edilen sonuçlar yerli yatırımcılara ait risk iştahı verilerinin doğrusal olduğunu ve eşik etkisinin olmadığını ortaya koymaktadır. Yabancı yatırımcılara ait risk iştahı serisinin ise doğrusal olmadığını ve eşik etkisinin var olduğu tespit edilmiştir. Ayrıca yabancı yatırımcılara ait risk iştahının düşme eğiliminde olduğu dönemlerde tahmin edilebildiği, artma dönemlerinde ise tahmin edilemediği ortaya konulmaktadır.

\section{Anahtar Sözcükler $\quad$ : $\quad$ Risk, Risk İştahı, Doğrusal Olmayan Birim Kök Testi.}




\section{Giriş}

19. yüzyıldan itibaren finansal piyasalarda yaşanan yüksek volatilite iki önemli kavram olan belirsizlik ve riskin önem kazanmasına neden olmuştur. Küreselleşmenin arttığı, ulusal politikaların ve krizlerin sadece ilgili ülkeyi değil tüm dünya ülkelerini etkilediği, finansal sınırların yok olmaya başladığı ve gerek finansal gerekse politik şartların artan değişkenlik hızı, belirsizlik ve risk kavramlarına ilişkin bakış açısında da farklılaşmaya neden olmuştur.

Belirsizlik kavramı beraberinde risk kavramını da doğurmaktadır. Ancak bu kavramlar birbirinden farklılık göstermektedir. Geleceğe yönelik kararlarda kullanılacak verilerin önceden kesin olarak bilinmesi mümkün değildir. Risk, bir olayın olasılık dağılımının bilindiği, belirsizlik ise, bu dağılımın bilinmediği durumları ifade etmektedir (Akalın, 1970: 201).

Risk Portekizce kökenli bir kelime olup, bir tehlikenin ortaya çıkma olasılığı ile ilgilidir (Yalçınkaya, 2004: 9). Finansal anlamda risk ise işletmenin finansal yönüyle ilgili planlanan veya beklenen herhangi bir durumun meydana gelmesi konusunda ortaya çıan sapma ihtimalidir (Emhan, 2009: 210). Risk, finansal yatırımın temel unsurlarından biri olmasına karşın, aynı zamanda, yatırımın en karmaşık ve anlaşılmayan özelliklerinden biri olarak kabul edilmektedir. Bunun temel nedeni ise her yatırımcının risk karşısındaki farklı tutumu ve davranışından kaynaklanmaktadır. Risk alma tutumları açısından yatırımcılar, riski seven, riske karşı kayıtsız ve riskten kaçan olarak üç gruba ayrılmaktadır (Başoğlu vd., 2001: 198). Finans alanında rasyonel insan davranışlarından birisi risk ve getiri karşılaştırması gerçekleştirmek ve yatırım sürecini buna göre şekillendirmek olarak ifade edilebilir. $\mathrm{Bu}$ bağlamda farklı risk ve getiriye sahip yatırım araçları arasında tercihler gerçekleştirilerek yatırım gerçekleştirilir. Markowitz (1952), riski getirinin varyansı olarak tanımlamış böylece onun matematiksel bir olgu olarak ele alınmasına olanak sağlamıştır. Markowitz'e göre yatırımcının yatırım tercihlerinin belirleyicileri, yatırımcının o portföye ilişkin istekliliği ve risk üstlenme derecesidir (Markowitz, 1959: 6). Portföy teorisi yatırımcıların temel olarak riskten kaçındığını yani benzer getirilere sahip iki varlık arasında seçim yapıldığında riski düşük varlığın tercih edileceğini ileri sürmektedir (Reilly \& Brown, 2002: 210). Bir yatırımcı için optimal portföy o varlığın riski ile beklenen getirisi arasındaki ilişkiye bakılarak oluşturulur. Dolaysıyla risk optimal portföyü oluşturmada dikkate alınacak temel unsurlardan biridir (Fama \& MacBeth, 1973: 608).

Pazar koşulları düşük belirsizlik ve yüksek getiriyi işaret ettiğinde yatırımcının risk taşıma istekliliği artar. Artan bu isteklilik finans literatüründe risk iştahı olarak ifade edilmektedir. Günümüzde risk iştahı farklı yöntemler kullanılarak hesaplanabilmekte ve yatırımcıların risk alma yönündeki tutumları risk iştahı aracılığı ile incelebilmektedir. Ülkemizde risk iştahı, farklı yatırımcı grupları için (tüm yatırımcılar, yerli yatırımcılar, yabancı yatırımcılar, yerli gerçek kişiler, yerli tüzel kișiler, yerli fonlar ve nitelikli yatırımcılar) Merkezi Kayıt Kuruluşu (MKK) ile Özyeğin Üniversitesi işbirliğince hesaplanmakta ve yatırımcıların bilgisine sunulmaktadır. 
Saraç, T.B. \& Ö. İskenderoğlu \& S. Akdağ (2016), "Yerli ve Yabancı Yatırımcılara Ait

Risk İştahlarının İncelenmesi: Türkiye Örneği”, Sosyoekonomi, Vol. 24(30), 29-44.

$\mathrm{Bu}$ çalışmanın amacı risk iştahının tahmin edilebilir olup olmadığını tespit etmek ve bu bağlamda farklı yatırımcı gruplarının gelecekteki risk alma tutumlarının öngörülüp öngörülemeyeceğini incelemektir. Bu doğrultuda 2008 - 2013 dönemi dikkate alınılarak yerli ve yabancı yatırımcılar için hesaplanmış olan risk iştahı serileri öncelikle geleneksel zaman serisi ekonometrisinde sıkça kullanılan ADF (Augmented Dickey Fuller Genelleştirilmiş Dickey Fuller), testi ve KPSS (Kwiatkowski Phillips Schmidt Shin) tesleri ile sınanmıştır. Daha sonra serilerde yapısal kırıklık olabileceği ihtimali değerlendirilerek Lee ve Strazicich (2003) birim kök testi ile daha farklı bir sınama gerçekleştirilmiştir. Son olarak ilgili serilerin doğrusal olmayabileceği düşünülmüş Caner ve Hansen (2001) birim kök testi kullanılarak son bir analiz daha gerçekleştirilmiştir. Bu bağlamda çalışma dört bölümden oluşmaktadır. İlk bölümde temel kavramlar olan risk, belirsizlik ve risk iştahı incelenerek konuya giriş yapılmış ikinci bölümde risk iştahı kavramı ve risk iştahı endeksi hakkında bilgi verilmiştir. Üçüncü bölümde risk iştahı konusunda gerçekleştirilen sınırlı sayıdaki çalışmalardan örneklerin yer aldığı literatür taraması bulunmaktadır. Dördüncü bölümde ise yerli ve yabancı yatırımcılar için hesaplanmış olan risk iştahı endeksindeki birim kök sınamalarına ilişkin bulgulara yer verilmiştir. Son bölümde ise sınamalardan elde edilen bulguların yorumlanmasına yönelik sonuç kısmı bulunmaktadır.

\section{Kavramsal Çerçeve}

Yatırımcılar portföylerini oluştururken tercihlerini risk ve beklenen getiriye göre yaparlar. Bu amaçla yatırımcılar portföylerin risk ve getirilerine göre fayda değerlerini oluştururlar. Buna göre faydanın ölçülüp ölçülemeyeceği tartışmaları ortaya atılmaktadır. Faydanın ölçümü ile ilgili olarak iki yaklaşım bulunmaktadır. İlk yaklaşım Kardinalist Okul olarak nitelendirilen ve faydanın ölçülebilir olduğunu ileri süren yaklaşımdır. Bu yaklaşıma göre fayda, tam belirlilik altında faydanın parasal olarak yatırımcının bir birim ek varlık için harcamak arzusunda olduğu para miktarı olarak ölçülebilir. İkinci yaklaşım olan Ordinalist Okul ise faydanın ordinal bir büyüklüğe sahip ölçülemeyen bir olgu olduğunu ancak varlıkların fayda yönünden birbirleri ile karşılaştırılarak tercih sırasının belirlenebileceğini ileri sürer. $\mathrm{Bu}$ yaklaşımda çeşitli varlık bileşimleri arasında seçim yapabilmek için yatırımcının her varlık demetinden ne kadar fayda elde edeceğini bilmesi gerekli olmamakla birlikte yatırımcının varlık demetlerini her bir demetten elde ettiği fayda düzeyine göre bir sırlamaya tabi tutması yeterlidir (Koutsoyiannis, 1997: 16). Bir anlamda bu yaklaşımda portföyler faydasına göre sıralanmaktadır. Yatırımcı açısından cazip risk-getiri bileşimine sahip portföyler daha yüksek fayda değerleri verecektir. Portföylerin beklenen getirisi yüksekse daha çok fayda değeri, portföylerin riski yüksek ise daha düşük fayda değer alacaktır. Bu yapıyı ifade edebilecek fayda fonksiyonlarının biride faydayı, beklenen getiri, varyans ve riskten kaçınma değerleriyle açıklayan $F=E(R)-0,005 A \sigma^{2}$ denkliğidir. Buna göre F faydayı, E(R) Beklenen getiri, $\sigma$ Standart Sapmayı göstermektedir, A ise yatırımcının riskten kaçınma derecesini göstermektedir (Korkmaz \& Ceylan, 2012: 472). İlgili denklikte A olarak bulunan ve yatırımcının riske karşı tutumunu gösteren değer 1 ile 10 arasında değişmekte olup yatırımcının risk tercih profilini ortaya koymaktadır. Finans literatürü Risk karşısındaki yatırımcı davranışları üçe ayrılmaktadır. Birincisi riski sevmeyen riskten kaçan yatırımcı tipidir. İkincisi riske karşı nötr olan, riskle ilgilenmeyen yani kayıtsız kalan 
yatırımcı tipidir. Üçüncüsü ise riski seven, riskten korkmayan yatırımcı tipidir (Illing \& Aaron, 2005: 1). Aynı ilintide yer alan risk iştahı kavramı ise yatırımcıların riskten kaçınma derecesi olarak ifade edilmiştir. Ancak riskten kaçınma ile risk iştahı kavramı farklılık arz etmektedir. Bu bağlamda Gai ve Vouse (2004) ve Misina (2005) çalışmalarında risk iştahı ile riskten kaçınmanın farklı kavramlar olduğu ifade edilmiştir. Riskten kaçınma yatırımcının içsel bir parçasıdır ve zamanla sık değişmeyen bir parametredir. Ancak risk iştahı, riskten kaçınmadan biraz daha farklıdır ve finansal sıkıntı ve makroekonomik belirsizliklerin olduğu zamanlarda periyodik olarak değişir (Misina, 2005: 23). Risk iştahı piyasa dinamiklerinden kaynaklanan bir sonuç, riskten kaçınma ise yatırımcı risk alma tercihi olarak ifade edilebilir.

Gai ve Vouse (2004) çalışmasında risk iştahı yatırımcıların risk taşıma istekliliği olarak tanımlanmaktadır. Risk iştahı hem yatırımcıların belirsizliklerden hoşlanmama derecesine hem de belirsizliklerin seviyesine bağlıdır. Belirsizlik seviyesi ise makroekonomik koşullara bağlıdır. Yatırımcıların belirsizliklerden hoşlanmama derecesi ise kişisel tercih olarak ifade edilebilir (Shen \& Hu, 2009: 26).

Risk iştahının tanımlanması, risk yönetimi stratejisinin şekillenmesi ve anlaşılması açısından da önem arzetmektedir. Risk iştahı yatırımcıların stratejik hedeflerini ve planlanan projelerini gerçekleştirmek için kapasitesi dâhilinde üstlenilmeye istekli toplam risk seviyesine şeklinde tanımlanabilir (Barfield, 2014: 9). Risk iştahı temelde iki ana unsurdan etkilenmektedir. Bunlar çerçevesi makroekonomik koşullar tarafından çizilen belirsizlik düzeyi ile riskten kaçınma tercihi olarak ifade edilebilir (Kalafatcılar \& Keleş, 2011: 2). Bu durum Şekil 1'de incelenebilir.

Şekil: 1

Risk Primi ve Risk İştahı Arasındaki İlişki

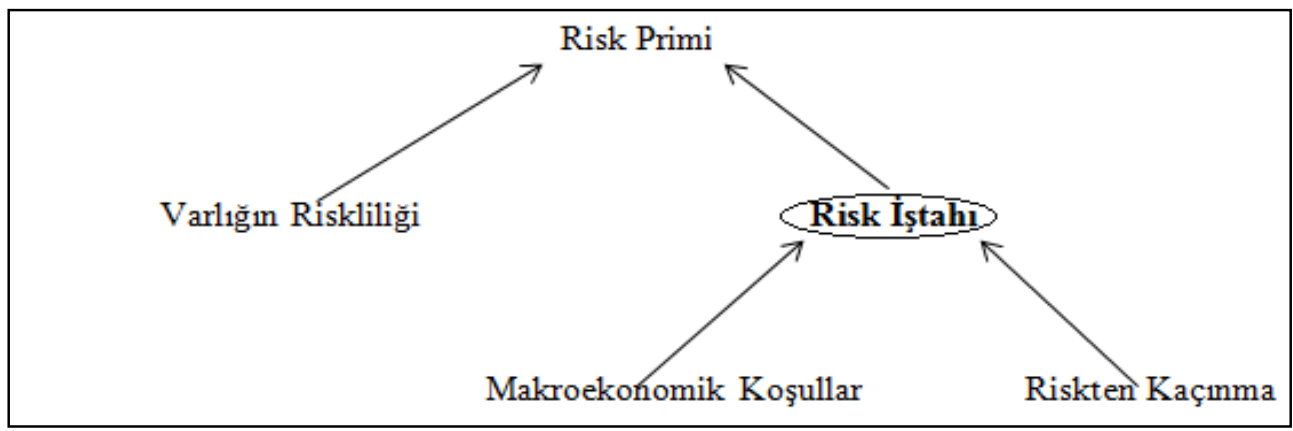

Kaynak: (Gai \& Vause, 2006).

Şekil 1 incelendiğinde makroekonomik koşullar ve riskten kaçınmanın risk iştahını doğrudan etkilediği görülebilir. Finansal sıkıntıların arttığı, ekonomik daralma ve durgunluk gibi örneklendirilen, makroekonomik koşulların bozulduğu dönemlerde ve riskten kaçınmanın arttığı durumlarda risk iştahının azalması tam tersi zamanlarda ise risk iştahının 
Saraç, T.B. \& Ö. İskenderoğlu \& S. Akdağ (2016), "Yerli ve Yabancı Yatırımcılara Ait

Risk İştahlarının İncelenmesi: Türkiye Örneği”, Sosyoekonomi, Vol. 24(30), 29-44.

artması beklenmektedir. Riskten kaçınmanın kolay kolay değişmediği düşünüldüğünde risk iştahındaki değişimlerin temel kaynağı makroekonomik şartlardaki değişism olacaktır.

Risk iştahı doğrudan gözlemlenebilir değildir. Ancak sıklıkla varlıkların fiyat hareketlerini açıklayan bir faktör olarak anılmakta ve piyasa katılımcıları tarafından bunu ölçmek için çeşitli göstergeler kullanılmaktadır. Farklı piyasalarda çeşitli göstergeler bir araya getirilerek üretilen sayısal dizinlere bağlı endeksler kullanılarak risk iştahı ölçülmeye çalışılmaktadır (Hermasillo, 2008: 8). Bu bağlamda risk iştahını ölçmek amacıyla çeşitli endeksler kullanılmaktadır. Bunlar arasında küresel risk iştahını ölçmek amacıyla kullanılan Volatalite Endeksine (VIX) finans yazınında sıklıkla atıfta bulunulmaktadır. VIX endeksi, korku veya stres endeksi olarak da adlandırılmaktadır. Bunun dışında Credit Suisse adlı İsviçre bankası 1998'den bu yana küresel yatırım iştahını hem oynaklık hem de düzenlilik kriterlerine göre ölçen çeşitli endeksler (GRAI, CSFB) yayınlamaktadır. Benzer şekilde piyasalardaki oynaklık ve riski ölçen JP Morgan'ın likidite, kredi ve dalgalanma endeksi (LCVI), İsviçre merkezli UBS'in yatırımcı duyarlılığı endeksi (UBS), Merrill Lynch'in finansal stres endeksi (ML) ve Avusturalya merkezli Westpac risk iştahı endeksi (WP) gibi birçok farklı endeks bulunmaktadır.

Ülkemizde de risk iştahı ölçmek amacıyla risk iştahı endeksi kullanılmaktadır. Bu amaçla 2005 yılından bu yana Yatırımcı Risk İştahı Endeksi (RISE) Merkezi Kayıt Kuruluşu ve Özyeğin Üniversitesi desteğiyle hesaplanıp yayımlanmaktadır. RISE geçmiş herhangi bir dönemde 5.000 TL. ve üzeri hisse senedi portföy değerine sahip her yatırımcının haftalık portföy değişimlerinden yola çıkılarak hesaplanan haftalık bir endekstir. Endeks, yatırımcıların her Cuma günü sahip olduğu hisse senedi ve A tipi yatırım fonu toplam portföy değeri değişimlerinin BIST100 endeksindeki değişimlerinden arındırılmış halleri kullanılarak hesaplanmaktadır. İlgili haftadaki düzeltilmiş portföy değerinden, önceki 52 haftalık değerlerinin ağırlıklı ortalaması çıkartılarak, her bir yatırımcının o hafta kendi normalinden ne kadar sapma gösterdiği hesaplanmaktadır. Oluşan bu sapmalar matrisi üzerinden, yatırımcılara ‘ 0 ’ ve ‘100' aralığında değişen skorlar verilmekte olup bu skorların yatırımcıların o haftaki portföy büyüklüklerinin toplam piyasa büyüklüğüne oranına göre ağırlıklı ortalaması alınarak tüm piyasa için genel bir risk iştahı endeksi hesaplanır.

Piyasalarda her bir yatırımcı türünün risk algısının farklı olması nedeniyle tüm yatırımcıları kapsayan genel RISE endeksinin yanı sıra altı farklı yatırımcı grubu için de ayrı endeksler hesaplanmaktadır. Bu yatırımc1 gruplar1 "Yerli Yatırımcılar", "Yabanc1 Yatırımcılar", "Yerli Gerçek Kişiler", "Yerli Tüzel Kişiler", "Yerli Fonlar" ve "Nitelikli Yatırımcılar"dan oluşmaktadır. Ortaya çıkan bu endekslerden her biri "50" eşik değerine göre ayrı ayrı kalibre edilerek, birbirleri ile karşılaştırılabilir olmaları sağlanmaktadır.

\section{Literatür Taraması}

Literatür taraması esnasında risk iştahı konusunda gerçekleştirilen sınırlı sayıda uygulamalı çalışmaya rastlanmıştır. İlgili çalışmaların tek bir eğilimi incelediğinden söz edilememektedir. Bu bağlamda makroekonomik faktörler ile risk iştahı arasındaki ilişkiyi inceleyen Haugen (2006) çalışmasında Bayes yaklaşımını kullanarak risk iştahı ile 
makroekonomik faktörler arasında istatistiksel olarak anlamlı bir ilişki olduğu sonucuna ulaşmıştır. Konuya daha farklı bir açıdan bakan Shem ve Hu (2007) çalışmasında ise finansal krizler, risk iştahı ve borsa getirisi üzerine bir dizi uygulama gerçekleştirilmiş ve Tayvan bankalarının risk iştahı endeksi (RAI) ile ulusal krizlerin ve Tayvan Borsası getirilerinin arasındaki ilişki regresyon modeli ile test edilmiştir. Analiz sonucunda yerel krizlerin RAI endeksinde önemli bir düşüşe neden olduğu, ayrıca RAI endeksi ile borsa getirileri arasında negatif bir ilişki olduğu sonucuna ulaşmıştır. Çokuluslu bir çalışma olan Adrian, Etula ve Shin (2009) çalışmasında ise Türkiye'nin de içerisinde yer aldığ 23 ülkenin döviz kurlarındaki (dolar) değişim ile küresel risk iştahı endeksi (VIX) ile arsındaki ilişki incelenmiştir. Çalışma sonucunda döviz kuru değişimimi ile risk iştahı arasında istatistiksel olarak anlamlı olduğu sonucuna ulaşılmıştır. Shem ve Hu (2007) ve Hermosillo (2008), çalışmasına benzer şekilde yatırımcıların risk iştahı ile küresel piyasalarda meydana gelen krizler arasındaki ilişki incelenmiştir. Hermosillo (2008) çalışmasında içerisinde Türkiye'nin ve Euro Bölgesinin yer aldığı 17 ülkenin tahvil fiyatları ile küresel risk iştahı endeksi (VIX) kullanılarak risk iştahı ile tahvil fiyatları arasında anlamlı bir ilişki olduğu tespit edilmiş ve çalışmaya konu ülkelerde yaşanılan finansal krizlerin risk iştahı endeksini negatif etkilediği sonucuna ulaşılmıştır.

\section{Metodoloji}

Yule (1926) çalışması makroekonomik verilerin analizinde durağanlık konusuna dikkat çeken ilk çalışmalardan birisidir. Durağanlık zaman serisinin ortalamasının ve varyansının zamandan bağımsız olması şeklinde ifade edilebilir. Durağan olmayan zaman serileri ile gerçekleştirilecek çalışmaların standart istatistiksel yöntemler ile değerlendirilemeyeceği Nelson ve Plosser (1982) çalışmasında ifade edilmektedir. Durağanlığın test edilmesinde Dickey ve Fuller (1979, 1981) çalışmasında geliştirilen Dickey Fuller ve Genişletilmiş Dickey Fuller (ADF), Philips ve Perron (1988) (PP) testleri yaygın olarak kullanılan önemli testlerdir. Bununla birlikte Kwiatkowski, vd. (1992) çalışmasında geliştirilmiş olan KPSS testide durağanlık testi için boş hipotez olarak trendden arındırılmış serinin durağanlığı lagranj çarpanı ile sınamaktadır.

Kullanılan bütün birim kök ve durağanlık testlerinin varsayımları, boş hipotezleri, uygulamaya konu edilen örneklem büyüklüğü gibi sebeplere bağlı olarak elde edilen sonuçlar testler arasında farklılık gösterebilmektedir. Örneğin ADF testi örneklem büyüklüğüne, seçilen gecikme uzunluğuna ve istatistiksek güven düzeyine bağlı olarak çok farklı sonuçlar verebilmektedir Schwert (1989) ve Campbell ve Perron (1991). Ayrıca Schwert (1989) ve Blake ve Fomby (1997) çalışmalarında PP testinin örneklem büyüklüğü geniş serilerde sağlıklı sonuçlar verdiği ancak asimptotik dağılım yüzünden oluşan örneklem çarpıklığı sebebiyle zayıf olduğu vurgulanmıştır. PP testinde bulunan örneklem büyüklüğü sorunları KPSS testinde de mevcuttur. İlgili testlerin yapısal özelliklerinden kaynaklanan eksiklikler yüzünden sonuçlarının güvenilirliği tartışması çok daha fazla genişletilebilir.

Uygulanan testin yapısal özelliği dışında kalan sebeplerden kaynaklanan sorunlarda sonuçları tutarsız hale getirebilmektedir. Örneğin Dickey ve Pantula (1987) çalışmasında açıklanan çoklu birim kök olması durumu, Joyeux (1980) ve Hosking (1981) çalışmasında 
ortaya konulan parçalı durağanlığın varlığı, Schwert (1989) çalışmasında ifade edilen örneklem çarpıklığı, Peron (1989, 1990), Bai ve Perron (2003) çalışmalarında detaylı bir şekilde üzerinde durulan yapısal kırılmalar, Dickey, Hasza ve Fuller (1984) çalışmasında ifade edilen mevsimsel etkilerin varlığı, zaman serilerinde yer alan deterministik trendler gibi sebeplerle uygulanan testlerden elde edilen sonuçlar geçersiz olabilir.

Şu ana kadar açıklanan tüm testlerin ortak zayıf kabul edilebileceği bir alan yapısal kırılma konusudur. Zaman serisinde oluşan şokların seri üzerinde yol açtığ 1 kalıcı etkiler yapısal kırıklığa neden olabilmektedir. Diğer bir ifade ile Zaman serileri farklı dönemlerde, değişik deterministik trendler etrafında durağan olabilmektedir. Bu değişiklikler; sabit terimde ve/veya eğimde meydana gelen yapısal kırılmalardan kaynaklanabilmektedir. $\mathrm{Bu}$ kırılmalara; savaş, barış, doğal afetler, terör olayları, politika değişiklikleri ve ekonomik krizler neden olabilir. Bu yapısal kırılmaları dikkate almadan yapılan birim kök analizleri hatalı sonuçlar verebilmekte ve gerçekte durağan olan serilerin yapılan yeni sınamalar sonucunda durağan olmadıkları gibi bir durum ortaya çıkabilmektedir (Perron, 1989). İlgili durumun tam tersi olarak yapısal kırılma olduğu halde yapısal kırılmalara yer vermeyen testler yanlış biçimde birim kök olduğu yönünde sapmalı sonuçlarda vermektedir (Charemza \& Deadman, 1997). Yapısal kırıklık altında mevcut birim kök testleri ile sınama gerçekleştirmek sağlıklı sonuçlar vermeyecektir. Literatürde yapısal kırılmanın içsel veya dışsal dinamiklerden kaynaklanmasına, tek veya birden fazla kırılmanın olmasına veya kırılma tarihinin bilinip bilinmemesine bağlı olarak geliştirilmiş farklı birim kök testleri mevcuttur. Perron (1989) Christiona (1992), Lumsdaine ve Stock (1992), Zivot ve Andrews (1992), Perron ve Vogelsang (1992), Perron (1997), Lumsdaine ve Papell (1997), Ng-Perron (2001), Lee ve Strazicich (2003, 2004), Carrion-i-Silvestre vd. (2009) çalışmaları bunlara örnek verilebilir. Bu testler arasında Lee ve Strazicich $(2003,2004)$ testleri ADF tipi yapısal kırılmalara izin veren testlerden farklı olarak hatalı reddetme problemini önlemekle birlikte bir ve iki kırılma için yapısal kırılma tarihlerini tespit edebilmektedir.

Şu ana kadar ifade edilen birim kök analizleri zaman serilerinin doğrusal olduğu varsayımı altında bir takım analizler gerçekleştirmekteydi. Ancak analize konu seriler doğrusal özellikler göstermeyebilir. Geleneksel birim kök testleri ilgili zaman serisinin doğrusal bir yapıya sahip olduğunu kabul etmektedir. Ancak ilgili zaman serisi doğrusal özellikler sergilemeyebilir. Bu durumda geleneksel birim kök testlerinin kullanılması yanlı ve hatalı sonuçlara yol açabilir. Örneğin Pippenger ve Goering (1993) çalışmasında ADF testinin doğrusal olmayan zaman serilerinde başarısız olduğunu kanıtlayan sonuçlar tespit edilmiştir. Ayrıca Enders ve Granger (1998) ve Enders (2001) çalışmalarında doğrusal olmayan zaman serilerinde ADF testi uygulanamayacağına yönelik saptamalar mevcuttur. Doğrusal olmayan süreçlere sahip zaman serileri Caner ve Hansen (2001) çalışmasında önerilen Caner ve Hansen birim kök testi ile incelenebilir.

Caner ve Hansen (2001) tarafindan geliştirilen doğrusal olmayan birim kök testi (1) no.lu denklem ile ifade edilen iki rejimli TAR (Threshold Autoregressive) modeline dayanmaktadir. 


$$
\Delta y_{t}=\theta_{1}^{\prime} x_{t-1} 1_{\left\{Z_{t-1}<\lambda\right\}}+\theta_{2}^{\prime} x_{t-1} 1_{\left\{Z_{t-1} \geq \lambda\right\}}+e_{t}
$$

(1) no.lu denklemde $t=1, \ldots, T$ ve $x_{t-1}=\left(y_{t-1} r_{t}^{\prime} \Delta y_{t-1}, \ldots, \Delta y_{t-k}\right)^{\prime}, 1_{\{\bullet\}}$ gösterge fonksiyonunu $e_{t}$ ortalaması sıfır, varyansı sabit ve bağımsız dağılmış hata terimini, $r_{t}$ sabit terim ve trend, içeren deterministik bileşenler vektörünü ifade etmektedir. $m \geq 1$ olması koşulu ile $Z_{t}$ ise $Z_{t}=y_{t}-y_{t-m}$ şeklinde oluşturulmaktadır. Modelde $\lambda$ (eşik değer) bilinmemekte ve $\theta_{1}$ ve $\theta_{2}$ 'ye ait bileşenler aşağıdaki şekilde incelenmiştir.

$$
\theta_{1}=\left(\begin{array}{l}
\rho_{1} \\
\beta_{1} \\
\alpha_{1}
\end{array}\right) \quad \theta_{2}=\left(\begin{array}{l}
\rho_{2} \\
\beta_{2} \\
\alpha_{2}
\end{array}\right)
$$

Yukarıdaki vektörlerde, $\rho_{1}$ ve $\rho_{2} y_{t-1}$ değişkenine ait eğim katsayılarını, $\beta_{1}$ ve $\beta_{2}$ deterministik bileşenlere ait eğim katsayılarını, $\sigma_{1}$ ve $\sigma_{2}$ her iki rejimdeki $\left(\Delta y_{t-1}, \ldots, \Delta y_{t-k}\right)$ değişkenlerine ait eğim katsayılarını göstermektedir. Bu açıklamalar ışığında, incelenen serinin birim kök içerip içermediği noktasında iki durum ortaya çıkmaktadır. Buna göre birinci durumda, seri her iki rejim birim kök içerebilir, ikinci durumda ise seri bir durumda birim kök içerebilir diğer durumda ise birim kök içermeyebilir. Bu durumlar dikkate alınarak, Caner ve Hansen (2001) çalışmasında incelenen serinin birim kök içerip içermediği noktasında $R_{2 T}$ ve $R_{1 T}$ istatistiklerini oluşturulmuş ve $R_{2 T}=t_{1}^{2}+t_{2}^{2}$ ile ifade edilen çift taraflı Wald istatistiğinin $R_{1 T}=t_{1}^{2} I_{\left\{\hat{\rho}_{1}<0\right\}}+t_{2}^{2} I_{\left\{\hat{\rho}_{2}<0\right\}}$ şeklinde ifade edilen tek taraflı Wald istatistiğine göre daha düşük güce sahip olması nedeniyle $R_{1 T}$ istatistiğinin kullanılması gerektiği ileri sürülmüştür. $R_{1 T}$ istatistiğinin anlamlı olması halinde incelenen serinin birim kök içermediğine karar verilmekte fakat serinin hangi rejimde birim kök içerip içermediğinin tespit edilmesi için $t_{1}$ ve $t_{2}$ istatistikleri kullanılmaktadır. Eğer $t_{1}$ istatistiği anlamlı ise seri birinci rejimde birim kök içermemekte, $t_{2}$ istatistiği anlamlı ise seri incelenen ikinci rejimde birim kök içermemektedir (Caner \& Hansen, 2001; Madsen, 2008).

$\mathrm{Bu}$ çalışmada kapsayıcı bir bakış açısı sağlamak amacıyla ADF ve KPSS testleri ile risk iştahı incelenmiş daha sonra Lee ve Strazicich testi ile bir veya birden fazla yapısal kırılma olup olmadığı sınanmış ve son olarak serinin doğrusal olmaması ihtimali dâhilinde 
Caner ve Hansen (2001) çalışmasında önerilen doğrusal olmayan birim kök testi gerçekleştirilmiştir.

\section{Veri}

Çalışmada kullanılan Risk İştahı Endeksi (RISE) verileri Merkezi Kayıt Kuruluşu (MKK)'den elde edilmiştir. RISE endeksi verilerinin hesaplanması 2005 yılından bu yana devam etse de verilerin düzenli hesaplandığı dönem 2008 yılının ilk haftasından başlamaktadır. Bu çalışmada da 2008 yılının ilk haftası ile 2013 yılının son haftası arası dönem (313 veri) haftalık olarak analizlere dahil edilmiştir. Yerli yatırımcılar ve yabancı yatırımcılara ait RISE verileri çalışmaya dâhil edilerek risk iştahının tahmin edilebilir olup olmadığı farklı yöntemlerle incelenmeye çalışılmıştır.

Tablo 1'de yerli ve yabancı yatırımcılar için tanımlayıcı istatistikler incelenebilir. Tanımlayıcı istatistikler incelendiğinde yerli yatırımcıların risk iştahı ortalamasının yabancı yatırımcılardan yüksek olduğu görülmekle beraber standart sapmaya bağlı olarak yabancı yatırımcıların risk iştahı dalgalanmasının yerli yatırımcılardan daha yüksek olduğu söylenebilir.

Tablo: 1

Tanımlayıcı İstatistikler

\begin{tabular}{|c|c|c|}
\hline İstatistikler & Yerli Yatırımcılar & Yabancı Yatırımcılar \\
\hline Ortalama & 50,16 & 43,42 \\
\hline Medyan & 50,82 & 44,27 \\
\hline Maksimum & 77,27 & 76,28 \\
\hline Minimum & 16,02 & 8,60 \\
\hline Std. Sapma & 12,58 & 13,33 \\
\hline Gözlem Sayısı & \multicolumn{2}{|c|}{313} \\
\hline
\end{tabular}

Tablo: 2

ADF ve KPSS Birim Kök Testi Sonuçları

\begin{tabular}{|c|c|c|c|c|}
\hline \multirow{2}{*}{ Seri } & \multicolumn{2}{|c|}{ ADF } & \multicolumn{2}{c|}{ KPSS } \\
\cline { 2 - 5 } & $\mathrm{a}$ & $\mathrm{b}$ & $\mathrm{a}$ & $\mathrm{b}$ \\
\hline Yerli Yatırımcılar & $\mathbf{- 5 . 8 4 ^ { ( \mathbf { 1 } ) } ( \mathbf { 1 } )}$ & $\mathbf{- 5 . 8 3}^{(\mathbf{1})}(\mathbf{1})$ & $\mathbf{0 . 1 1}^{(\mathbf{1})}(\mathbf{1 1})$ & $\mathbf{0 . 0 8}^{(\mathbf{1})}\left(\mathbf{1 1}^{\mathbf{1})}\right.$ \\
\hline Yabancı Yatırımcılar & $\mathbf{- 6 . 6 4}^{(\mathbf{1})}(\mathbf{0})$ & $\mathbf{- 6 . 6 4}^{(\mathbf{1})}(\mathbf{0})$ & $\mathbf{0 . 1 0}^{(\mathbf{1 )}}(\mathbf{1 1})$ & $\mathbf{0 . 0 8}^{(\mathbf{1})}(\mathbf{1 1})$ \\
\hline
\end{tabular}

Notlar:

1) Parantez içerisindeki değerler, ADF testi için gecikme uzunluklarını, KPSS testi için ise uygun band genişliklerini göstermektedir.

2) ADF testi için uygun gecikme uzunluğunun belirlenmesinde Schwarz Bilgi kriteri, KPSS testinde uygun band genişliğinin belirlenmesinde ise Newey-West Bandwidth kriteri kullanılmıştır.

3) a: Sabitli Modeli, b: Sabitli ve Trendli Modeli, (l) ifadesi ilgili serinin yüzde 5 önem düzeyinde birim kök içermediğini ifade etmektedir.

Yerli ve yabancı yatırımcılar açısından risk iştahının tahmin edilebilir olup olmadığını incelemek amacıyla öncelikle geleneksel birim kök testleri olan ADF ve KPSS testleri ile birim kök sınaması gerçekleştirilmiştir. İlgili testlerin sonuçları Tablo 2'de görülebilir. Tablo 2 incelendiğinde tüm yatırımcı gruplarına ait risk iştahı serilerinin $\% 5$ önem düzeyinde birim kök içermediği, diğer bir ifade ile durağan olduğu görülmüştür. Bu sonuç ilgili serilerde ortalamaya dönme eğilimini gösteriyor olabilir. Ortalamaya dönme 
eğilimi ise ilgili serilerin tahmin edilebileceğini göstermektedir. Tablo 2'de yer alan sonuçlar incelendiğinde ADF ve KPSS testi sonuçlarının tamamında yerli ve yabancı yatırımcıların risk iştahlarının ortalamaya dönme eğilimi içerisinde olduğu görülmektedir. Fakat yapısal kırılmayı dikkate almayan bu testlerin yerine olası yapısal kırılmaları dikkate alan LeeStrazicich (2003) birim kök testinin uygulanması konu ile ilgili daha geniş bilgileri sağlayabilir. Buna göre gerçekleştirilmiş olan Lee ve Strazicich (2003) birim kök testi sonuçları Tablo3'de sunulmuştur. Lee-Strazicich (2003) birim kök testi sonuçlarına göre serilerin tümünün birim kök içermediği belirlenmiştir. Bu sonuçlar, serilerdeki yapısal kırılmalar dikkate alındığında serilerin durağan olmadığını gösteren temel hipotezin reddedildiğini göstermektedir.

\section{Tablo: 3}

Lee ve Strazicich (2003) Birim Kök Testi Sonuçları

\begin{tabular}{|cc|c|c|c|}
\hline Seriler & $\begin{array}{c}\text { Sabitli } \\
\text { (t-ist.) }\end{array}$ & Kırılma Tarihleri & Sabit ve Trendli (t-ist.) & $\begin{array}{c}\text { Kırılma } \\
\text { Tarihleri }\end{array}$ \\
\hline \multirow{2}{*}{ Yerli Yatırımcılar } & $-6.33^{(1)}(2)$ & $\begin{array}{l}28.11 .2008 \\
02.12 .2011\end{array}$ & $-7.29^{(1)}(4)$ & 30.01 .2009 \\
\hline \multirow{2}{*}{ Yabancı Yatırımcılar } & $-6.68^{(1)}(2)$ & $\begin{array}{l}28.11 .2008 \\
02.12 .2011\end{array}$ & $-7.33^{(1)}(3)$ & 21.11 .2008 \\
\hline
\end{tabular}

\section{Notlar:}

1) Parantez içerisindeki değerler, uygun gecikme uzunlukların göstermektedir.

2) Sabitli model için yüzde 5 önem düzeyinde kritik değer -3.842; Sabitli ve trendli model için farkl kurlma zamanlar için yüzde 5 önem düzeyindeki kritik değerler: -5.59, -5.74, -5.67, -5.71, -5.65, -5.73 olarak ifade edilmektedir. Bknz. Lee- Strazicich, 2003: 1084.

3) ( $t$-ist.) " $t$ " istatistik değerini ifade etmektedir.

4) (l) ifadesi ilgili serinin yüzde 5 önem düzeyinde birim kök içermediğini ifade etmektedir.

Her ne kadar serilerdeki yapısal kırılmaları dikkate alan birim kök testlerinin üstün yönleri bulunsa da, gerek yapısal kırılmayı dikkate almayan gerekse yapısal kırılmayı dikkate alan birim kök testleri ilgili zaman serisinin doğrusal bir yapıya sahip olduğunu kabul etmektedir. Yerli ve Yabancı yatırımcılar serisi için Caner ve Hansen (2001) tarafından geliştirilen $R_{I T}$ ve $R_{2 T}$ birim kök testlerini yapabilmek için kalıntı kareleri toplamını (KKT) minimum eden değer olan gecikme parametresinin belirlenmesi gerekmektedir. Bu nedenle Caner ve Hansen (2001) birim kök testi gerçekleştirilmiş ve bunun için öncelikle çalışmada kullanılan yerli ve yabancı yatırımcılar için risk iştahı serisinin doğrusal olup olmadığ 1 Wald testi ile incelenmiş, elde edilen sonuçlar Tablo 4 ve Tablo 5'de sunulmuştur.

Tablo 4 incelendiğinde yerli yatırımcılara ait risk iştahının bir eşik değere sahip olmadığı tespit edilmiştir. Buna göre ilgili serinin doğrusal özellikler göstermediği hipotezi reddedilmekle birlikte yerli yatırımcılar için test sonlandırılmıştır. Buna göre yerli yatırımcılara ait risk iştahının doğrusal özellikler gösterdiği söylenebilir. 
Tablo: 4

Yerli Yatırımcılar İçin Wald Testi Sonuçları

\begin{tabular}{|c|c|c|c|c|}
\hline \multirow{2}{*}{ Gecikme Uzunluğu } & \multicolumn{2}{|c|}{ Sabitli Model } & \multicolumn{2}{c|}{ Sabitli ve Trendli Model } \\
\cline { 2 - 5 } & Wald İstatistiği & Olasılık Değeri & $\begin{array}{c}\text { Wald } \\
\text { İstatistiği }\end{array}$ & $\begin{array}{c}\text { Olasıllık } \\
\text { Değeri }\end{array}$ \\
\hline 1 & 22.10 & 0.551 & 23.70 & 0.497 \\
\hline 2 & 22.70 & 0.490 & 22.70 & 0.599 \\
\hline 3 & 25.00 & 0.356 & 24.80 & 0.467 \\
\hline 4 & 18.50 & 0.787 & 23.90 & 0.498 \\
\hline 5 & 31.70 & 0.088 & 32.00 & 0.094 \\
\hline 6 & 20.50 & 0.669 & 20.70 & 0.740 \\
\hline 7 & 20.70 & 0.643 & 21.40 & 0.662 \\
\hline 8 & 18.60 & 0.779 & 20.10 & 0.784 \\
\hline 9 & 19.60 & 0.717 & 22.40 & 0.602 \\
\hline 10 & 22.70 & 0.478 & 24.30 & 0.473 \\
\hline 11 & 25.40 & 0.313 & 26.60 & 0.306 \\
\hline 12 & 29.30 & 0.128 & 33.10 & 0.094 \\
\hline
\end{tabular}

Notlar:

1) Wald testi gerçekleştirilirken maksimum gecikme uzunluğu çalışmadaki gözlem sayısı dikkate alınarak 12 (on iki) olarak alınmıştır.

Tablo: 5

Yabancı Yatırımcılar İçin Wald Testi Sonuçları

\begin{tabular}{|c|c|c|c|c|}
\hline \multirow{2}{*}{ Gecikme Uzunluğu } & \multicolumn{2}{|c|}{ Sabitli Model } & \multicolumn{2}{c|}{ Sabitli ve Trendli Model } \\
\cline { 2 - 5 } & Wald İstatistiği & Olasılık Değeri & $\begin{array}{c}\text { Wald } \\
\text { İstatistiği }\end{array}$ & $\begin{array}{c}\text { Olasılık } \\
\text { Değeri }\end{array}$ \\
\hline 1 & 21.20 & 0.532 & 21.20 & 0.694 \\
\hline 2 & 20.60 & 0.673 & 21.70 & 0.671 \\
\hline 3 & 18.30 & 0.809 & 20.10 & 0.768 \\
\hline 4 & 17.30 & 0.863 & 20.20 & 0.754 \\
\hline 5 & 25.20 & 0.327 & 26.30 & 0.349 \\
\hline 6 & 21.40 & 0.608 & 22.00 & 0.648 \\
\hline 7 & 20.50 & 0.637 & 21.00 & 0.701 \\
\hline 8 & 21.30 & 0.584 & 23.20 & 0.550 \\
\hline 9 & 26.40 & 0.265 & 27.40 & 0.278 \\
\hline 10 & 27.70 & 0.204 & 27.40 & 0.297 \\
\hline 11 & $\mathbf{3 8 . 1 0}$ & $\mathbf{0 . 0 1 3}$ & $\mathbf{3 8 . 8 0}$ & $\mathbf{0 . 0 2 4}$ \\
\hline 12 & 29.30 & 0.128 & 30.00 & 0.167 \\
\hline
\end{tabular}

Notlar:

1) Wald testi gerçekleştirilirken maksimum gecikme uzunluğu çalışmadaki gözlem sayısı dikkate alınarak 12 (on iki) olarak alınmıştır.

Tablo 5'deki sonuçlara göre, yüzde 5 önem düzeyinde yabancı yatırımcılara ait risk iştahının doğrusal bir yapıda olmadığı tespit edilmiştir. Tablo 5 'e göre yabancı yatırımcılara ait risk iştahı serisinde birim kök testlerini yapabilmek amacıyla kalıntı kareleri toplamını (KKT) minimize eden uzunluk 11'dir. Ayrıca KKT'yi minimize eden 11. gecikme uzunluğunda, olasılık değerinin istatistiksel olarak anlamlı olduğu görülmektedir. Buna göre $R_{I T}$ ve $R_{2 T}$ birim kök testlerinde, t-istatistik değerini ve olasılık değerini değerlendirmek için 11. gecikme uzunluğu kullanılacaktır. Dolayısıyla, yabancı yatırımcılara ait risk iştahı serisinin doğrusal olduğunu ve eşik etkisinin olmadığını ifade eden sıfır hipotezi reddedilerek alternatif hipotez kabul edilir. Alternatif hipotezin kabul edilmesi yabanc1 
yatırımcılara ait risk iştahı serisinin doğrusal olmadığını ve eşik etkisinin olduğunu ifade etmektedir. Buna göre ilgili seri iki rejimden oluşmaktadır, sabitli modelde eşik değeri 14,30, sabitli ve trendli model de ise $-18,40$ 'dır . Bu sonuçlara göre, Yabancı Yatırımcılar serisi için doğrusal olmayan birim kök testi gerçekleştirilmesi uygun olup ilgili testten elde edilen sonuçlar Tablo 6'da sunulmuştur.

Tablo: 6

Tek Taraflı ve Parçalı Birim Kök Testi Sonuçları

\begin{tabular}{|c|c|c|c|c|c|c|c|c|}
\hline \multirow{2}{*}{ Seriler } & \multicolumn{2}{|c|}{$R_{1 T}$ İst. Değeri } & \multicolumn{2}{c|}{$R_{2 T}$ İst. Değeri } & \multicolumn{2}{c|}{$t_{1}^{2}$ İst. Değeri } & \multicolumn{2}{c|}{$t_{2}^{2}$ İst. Değeri } \\
\cline { 2 - 9 } & $\mathbf{a}$ & $\mathbf{b}$ & $\mathbf{a}$ & $\mathbf{b}$ & $\mathbf{a}$ & $\mathbf{b}$ & $\mathbf{a}$ & $\mathbf{b}$ \\
\hline Yabancı Yatırımcılar & 31.60 & 26.40 & 31.60 & 26.40 & 5.02 & 3.99 & 2.54 & 3.23 \\
& $(0.000)$ & $(0.002)$ & $(0.000)$ & $(0.002)$ & $(0.000)$ & $(0.018)$ & $(0.105)$ & $(0.066)$ \\
\hline
\end{tabular}

Notlar:

1) Parantez içerisindeki değerler olasılık değerlerini göstermektedir.

2) $a$ : Sabitli, b: Sabitli ve Trendli modeli ifade etmektedir.

Tablo: 7

TAR Modeli Sonuçları

\begin{tabular}{|c|c|c|c|c|}
\hline \multirow{2}{*}{ Değişkenler } & \multicolumn{2}{|c|}{ Sabitli Model } & \multicolumn{2}{c|}{ Sabitli ve Trendli Model } \\
\cline { 2 - 5 } & Rejim 1 (n: 64) & Rejim 2 (n: 236) & Rejim 1 (n:47) & Rejim 2 (n: 253) \\
\cline { 2 - 5 } & $Z_{t-1}<-14.30$ & $Z_{t-1} \geq-14.30$ & $Z_{t-1}<-18.40$ & $Z_{t-1} \geq-18.40$ \\
\hline Sabit Terim & $32.20(7.030)$ & $7.270(3.190)$ & $17.90(12.400)$ & $10.20(3.110)$ \\
\hline Trend & - & - & $0.037(0.020)$ & $-0.005(0.006)$ \\
\hline$Y_{t-1}$ & $-0.781(0.156)$ & $-0.180(0.070)$ & $-0.824(0.206)$ & $-0.219(0.061)$ \\
\hline$\Delta Y_{t-1}$ & $0.163(0.188)$ & $0.002(0.093)$ & $-0.130(0.310)$ & $-0.023(0.087)$ \\
\hline$\Delta Y_{t-2}$ & $0.476(0.186)$ & $0.124(0.089)$ & $0.168(0.291)$ & $0.109(0.086)$ \\
\hline$\Delta Y_{t-3}$ & $0.420(0.180)$ & $0.025(0.087)$ & $0.192(0.259)$ & $0.022(0.083)$ \\
\hline$\Delta Y_{t-4}$ & $0.322(0.175)$ & $-0.013(0.085)$ & $-0.004(0.265)$ & $0.002(0.082)$ \\
\hline$\Delta Y_{t-5}$ & $-0.220(0.188)$ & $0.002(0.080)$ & $-0.590(0.278)$ & $0.014(0.078)$ \\
\hline$\Delta Y_{t-6}$ & $-0.048(0.207)$ & $0.004(0.077)$ & $-0.370(0.335)$ & $-0.302(0.075)$ \\
\hline$\Delta Y_{t-7}$ & $0.236(0.218)$ & $0.016(0.076)$ & $-0.112(0.315)$ & $-0.004(0.071)$ \\
\hline$\Delta Y_{t-8}$ & $0.065(0.197)$ & $-0.018(0.074)$ & $-0.207(0.291)$ & $-0.039(0.069)$ \\
\hline$\Delta Y_{t-9}$ & $0.356(0.184)$ & $-0.027(0.070)$ & $0.080(0.277)$ & $-0.034(0.069)$ \\
\hline$\Delta Y_{t-10}$ & $-0.307(0.164)$ & $-0.007(0.703)$ & $-0.546(0.242)$ & $-0.014(0.069)$ \\
\hline$\Delta Y_{t-11}$ & $-0.060(0.182)$ & $0.101(0.068)$ & $-0.427(0.285)$ & $0.088(0.067)$ \\
\hline$\Delta Y_{t-12}$ & $0.078(0.130)$ & $-0.024(0.063)$ & $-0.033(0.177)$ & $-0.014(0.061)$ \\
\hline
\end{tabular}

Notlar: 1) Parantez içerisindeki değerler standart hatalarl göstermektedir. 
$\mathrm{R}_{2 T}$ testine göre sabitli ve sabitli ve trendli modelde Yabancı yatırımcılar serisinde her iki rejimde birim kök olduğu temel hipotezi reddedilmektedir. Ancak serideki rejimlerin birinde birim kök varsa bu test sonuçları yetersiz kalmaktadır. Hangi rejimde birim kök olduğuna, hangi rejimin ise duran olduğuna ise $\mathrm{t}^{2}{ }_{1}$ ve $\mathrm{t}^{2}{ }_{2}$ istatistiğine bakılarak karar verilir. Birinci rejimi ifade eden $\mathrm{t}^{2}{ }_{1}$ istatistiğine göre birinci rejimde sabitli ve sabitli ve trendli modelde birim kök yoktur. Dolaysıyla birinci rejim durağandır. İkinci rejimi ifade eden $\mathrm{t}^{2}{ }_{2}$ istatistiğine göre e hem sabitli modelde, hemde sabitli ve trendli modelde birim kök vardır. Buna göre ikinci rejim durağan değildir.

Birim kök testlerinden yararlanılarak Yabancı Yatırımcıların risk iştahını gösteren serinin geçmiş değerlerine ait katsayıların tahmini Tablo 7'de gösterilmektedir. Her bir rejim için farklı modellerde kaç değişkenin dikkate alındığı, eşik altı ve eşik üstü modellerde tahmin katsayılarının neler olduğu ilgili tabloda incelenebilir.

\section{Sonuç ve Öneriler}

Risk iştahı yatırımcıların risk taşıma istekliliği olarak tanımlanmakta olup risk iştahı, finansal istikrarın bir ölçüsü olarak kabul edilmektedir. Finansal piyasalarda bir referans ölçüsü olarak kullanılan risk iştahı, hem ulusal bazda hem de uluslararası bazda farklı yöntemler ile ölçülmeye çalışılmaktadır. Bu amaçla farklı finansal kurumlar tarafından çeşitli risk iştahı endeksleri oluşturulmuş olup ilgili endeksler farklı frekanslarda yayınlanmaktadır. Türkiye'de bu amaçla MKK tarafından farklı yatırımcı grupları için hesaplanan risk iştahı endeksi haftalık frekansta ilan edilmektedir. Bu çalışmada yerli ve yabancı yatırımcılar için 2008 - 2013 dönemlerine ilişkin hesaplanan risk iştahı endekslerinin tahmin edilir formda olup olmadığı ADF, KPSS, Lee ve Strazicich (2003), Caner ve Hansen (2001) testleri ile incelenmiştir.

Çalışmadan elde edilen sonuçlar yerli yatırımcılar risk iştahı endeksinin doğrusal olduğunu, eşik etkisinin olmadığını ve tahmin edilebilir olduğunu ortaya koymaktadır. Ancak yabancı yatırımcılara ait risk iştahı serisinin doğrusal olmadığı ve eşik etkisinin var olduğu tespit edilmiştir. Dolayısıyla yabancı yatırımcılara ait risk iştahı serisinde ikili bir rejim oluşmuş olup bu rejimler düşüş ve artış olarak ifade edilebilir. Yabancı yatırımcıların risk iştahında düşüşün oluştuğu dönemde $t_{1}^{2}$ istatistiği birim kökün olmadığını ve artışın oluştuğu dönemde $t_{2}^{2}$ istatistiği birim kökün olduğunu göstermektedir. Bu sonuç finansal olarak değerlendirildiğinde yabancı yatırımcıların risk iştahlarının düşme eğiliminde olduğu dönemde risk iştahının tahmin edilebilir olduğunu ortaya koymakla birlikte risk iştahının artma eğiliminde olduğu dönemde tahmin yapılamayacağını ve kalıcı şokların varlığını ortaya koymaktadır. Risk iştahı endeksinin hesaplanma şekli değerlendirilerek varılacak bir diğer sonuçta piyasa dalgalanmalarının azaldığ 1 dönemlerde belirsizlikteki azalmaya bağlı olarak yabancı yatırımcıların risk iştahlarının tahmin edilebileceği sonucudur. Ayrıca piyasa dalgalanmasının arttığı dönemlerde yabancı yatırımcıların risk iştahlarının tahmin edilemeyeceği ve buna göre artan belirsizlik ortamının yabancı yatırımcıların risk iştahındaki değişimleri de belirsiz hale getirdiği söylenebilir. Yerli yatırımcılar açısından ise 
artan belirsizlik risk iştahını belirsiz hale getirmemekte olup yerli yatırımcıların risk iştahlarının tahmin edilebilir bir yapıda olduğu sonucuna varılabilir.

Yerli ve yabancı yatırımcıların risk iştahları arasındaki tespit edilen yapısal farklılığın sebebi bu çalışmanın kapsamı dışında tutulmuş olup, farklı yatırımcı grupları için risk iştahını belirleyen faktörlerin tespiti yeni bir çalışmanın konusunu oluşturacaktır.

\section{Kaynaklar}

Adrian, T. \& E. Etula \& H.S. Shin (2009), “Global Liquidity and Exchange Rates”, Unpublished Manuscript, Federal Reserve Bank of New York, Harvard University, and Princeton University.

Akalın, S. (1970), Yönetim Ekonomisi, Ege Üniv. İ.T.İ.A Yayını, İzmir.

Bai, J. \& P. Perron (2003), "Computation and Analysis of Multiple Structural Change Models", Journal of Applied Econometrics, (18), 1-22.

Balke, N.S. \& T.B. Fomby (1997), “Threshold Cointegration”, International Economic Review, $38(3), 627-45$

Banerjee, A. \& R.L. Lumsdaine \& J.H. Stock (1992), "Recursive and Sequential Tests of the Unit Root and Trend-Break Hypothesis: Theory and International Evidence", Journal of Business and Economic Statistics, 10, 271-287.

Barfield, R. (2014), Risk Appetite - How Hungry are You?, Pricewaterhousecoopers, Special Risk Management Edition, U.K.

Başoğlu, U. \& A. Ceylan \& İ. Parasız (2001), Finans: Teori, Kurum ve Araçlar, Ekin Kitabevi, Bursa.

Campbell, J.C. \& P. Perron (1991), "Pitfall and Opportunities: What Macroeconomists Should Know About Unit Roots", NBER Technical Working Paper.

Caner, M. \& B.E. Hansen (2001), “Threshold Autoregression with a Unit Root”, Econometrica, 69, 1555-96.

Carrion-i-Silvestre, J.L. \& D. Kim \& P. Perron (2009), "GLS-Based Unit Root Tests with Multiple Structural Breaks under Both the Null and the Alternative Hypotheses", Econometric Theory, 25, 1754-1792.

Charemza, W.W. \& D.F. Deadman (1997), New Directions in Econometric Practice, Cheltenham, Edward Elgar.

Christiano, L.J. (1992), "Searching for a Break in GNP”, Journal of Business and Economic Statistics, 10, 237-249.

Dickey, D.A. \& W. Fuller (1979), "Distribution of the Estimator for Autoregressive Timeseries with a Unit Root", Journal of the American Statistical Association, 74, 427-431.

Dickey, D.A \& D.P. Hasza \& W.A. Fuller (1984), “Testing for Unit Roots in Seasonal Time Series", Journal of American Statistical Association, 79, 355-367.

Dickey, D.A. \& G.V. Pantula (1987), "Determining the Order of Differencing in Autorregressive Processes", Journal of Business \& Economic Statistics, 5(4), 455-461.

Emhan, A. (2009), "Risk Yönetim Süreci ve Risk Yönetmekte Kullanılan Teknikler", Atatürk Üniversitesi İktisadi ve İdari Bilimler Dergisi, 23(3), 209-220. 
Enders, W. \& C.W.J. Granger (1998), "Unit-Root Tests and Asymmetric Adjustment With an Example Using the Term Structure of Interest Rates", Journal of Business and Economic Statistics, 16, 304-11.

Fama, E.F. \& J.D. Macbeth (1973), "Risk, Return, and Equilibrium: Empirical Tests", Journal of Political Economy, 81(3), 607-636.

Gai, P. \& N. Vause (2004), "Risk Appetite: Concept and Measurement", Financial Stability Review, Bank of England, December, 127-36.

Gai, P. \& N. Vause (2006), "Measuring Investors Risk Appetite", International Journal of Central Banking, 2(1), 167-188.

Granger C.W.J. \& R. Joyeux, (1980), "An Introduction to Long Memory Time Series Models and Fractional Differencing", J Time Ser Anal. 1(1), 15-29.

Haugen, P. (2006), "Financial Risk, Risk Appetite and the Macroeconomic Environment", Master Thesis of Science in Physics and Mathematics, Norwegian University.

Hermosillo, G.B. (2008), Investor's Risk Appetite and Global Financial Market Conditions, Washington: International Monetary Fund.

Hosking, J. (1981), "Fractional Differencing”, Biometrika, 68(1), 165-167.

Illing, M. \& M. Aaron (2005), “A Brief Survey of Risk-Appetite Indexes”, Financial System Review, Bank of Canada, 37-43.

Kalafatcılar, K. \& G. Keleş (2011), "Risk İştahı Endeksleri ve İfade Ettikleri”, Ekonomi Notları, TCMB, 2011-12.

Korkmaz, T. \& A. Ceylan (2012), Sermaye Piyasası ve Menkul Değer Analizi, 6. Baskı, Ekin Basım Yayın Dağıtım, Bursa.

Koutsoyiannis, A. (1997), Modern Mikro İktisat, Gazi Kitabevi, İkinci Bask1, Ekim, Ankara.

Kwiatkowski, D. \& P.C.B. Phillips \& P. Schmidt \& Y. Shin (1992), "Testing the Full Hypothesis of Stationary Against The Alternative of A Unit Root", Journal of Econometrics, 54, 159178.

Lee, J. \& M.C. Strazicich (2003), "Minimum Lagrange Multiplier Unit Root Test with Structural Breaks", Review of Economics and Statistics, 85(4), 1082-1089.

Lumsdaine, R.L \& D.H. Papell (1997), "Multiple Trend Breaks and the Unit Root Hypothesis", Review of Economics and Statistics, 79(2), 212-218.

Madsen, J. \& V. Mishra \& R. Smyth (2008), “Are Labour Force Participation Rates Non-Stationary? Evidence from 130 Years for G7 Countries”, Australian Economic Papers, 47, 166-189.

Markowitz, H.M. (1952), "Portfolio Selection”, Journal of Finance, 7, 77-91.

Markowitz, H.M. (1959), Portfolio Selection, Library of Congress Catalog, United States of America.

Merkezi Kayıt Kuruluşu (2015), Risk İştahı Endeksi, <https://www.mkk.com.tr/risk-index>, 28.11.2015.

Misina, M. (2005), Benchmark Index of Risk Appetite, Bank of Canada, Monetary and Financial Analysis, September 15.

Nelson, C.R. \& C.R. Plosser (1982), "Trends and Random Walks in Macroeconomic Time Series: Some Evidence and Implications", Journal of Monetary Economics, 10, 139-162.

Ng, S. \& P. Perron (2001), "Lag Length Selection and the Construction of Unit Root Tests with Good Size and Power", Econometrica, 69, 1519-1554. 
Perron, P. (1989), "The Great Crash, the Oil-Price Shock, and the Unit-Root Hypothesis", Econometrica, (57), 1361-1401.

Perron, P. (1997), "Further Evidence on Breaking Trend Functions in Macroeconomic Variables", Journal of Econometrics, 80(2), 355-385.

Perron, P. \& T.J. Vogelsang (1992), "Nonstationarity and Level Shifts with an Application to Purchasing Power Parity", Journal of Business and Economic Statistics, 10, 301-320.

Phillips, P.C.B. \& P. Perron (1988), “Testing For A Unit Root İn Time Series Regression”, Biometrika, 75, 335-346.

Pippenger, M.K. \& G.E. Goering (1993), “A Note on the Empirical Power of Unit Root Testsunder Threshold Processes", Oxford Bulletin of Economics and Statistics, 55, 473-481.

Reilly, F. \& K.C. Brown (2002), Investment Analysis and Portfolio Management, 7th Published by Thomson, South Western, Cincinnati, $\mathrm{OH}$.

Schwert, G.W. (1989), “Tests for Unit Roots: A Monte Carlo Investigation”, Journal of Business \& Economic Statistics, 7(2), 147-159.

Shen, D.B. \& K.H. Hu (2007), "Bank Risk Appetite Measurement and the Relationship with Macroeconomic Factors: Case of Taiwan's Banks", International Journal of Information Systems for Logistics and Management, 3(1), 25-39.

Yalçınkaya, T. (2004), "Risk ve Belirsizlik Algılamasının İktisadi Davranışlara Yansımaları", Muğla Üniversitesi, İIBF Tartışma Tebliğleri, 2004/05, Muğla.

Yule, G.U. (1926), "Why do We Sometimes get Nonsense-Correlations between Time-Series? - A Study in Sampling and the Nature of Time-Series", Journal of the Royal Statistical Society, 89(1), 1-63.

Zivot, E. \& K. Andrews (1992), "Further Evidence on the Great Crash, the Oil Price Shock, and the Unit Root Hypothesis”, Journal of Business and Economic Statistics, 10(10), 251-70. 